\title{
GCU
}

Glasgow Caledonian

University

University for the Common Good

\section{Power sharing controller for modular dual active bridge DC/DC converter in medium voltage DC applications}

Harrye, Yasen A.; Aboushady, Ahmed A.; Ahmed, Khaled H.

Published in:

2017 IEEE 6th International Conference on Renewable Energy Research and Applications (ICRERA)

DOI:

10.1109/ICRERA.2017.8191131

Publication date:

2017

Document Version

Author accepted manuscript

Link to publication in ResearchOnline

Citation for published version (Harvard):

Harrye, YA, Aboushady, AA \& Ahmed, KH 2017, Power sharing controller for modular dual active bridge DC/DC converter in medium voltage DC applications. in 2017 IEEE 6th International Conference on Renewable Energy Research and Applications (ICRERA). IEEE, pp. 602-607. https://doi.org/10.1109/ICRERA.2017.8191131

\section{General rights}

Copyright and moral rights for the publications made accessible in the public portal are retained by the authors and/or other copyright owners and it is a condition of accessing publications that users recognise and abide by the legal requirements associated with these rights.

Take down policy

If you believe that this document breaches copyright please view our takedown policy at https://edshare.gcu.ac.uk/id/eprint/5179 for details of how to contact us. 


\title{
Power Sharing Controller for Modular Dual Active Bridge DC/DC Converter in Medium Voltage DC Applications
}

\author{
Yasen A. Harrye ${ }^{1 *}$, Ahmed A. Aboushady ${ }^{2}$, Khaled H. Ahmed ${ }^{3}$ \\ ${ }^{1}$ School of Engineering, University of Aberdeen, 1-5 Elphinstone Road, Aberdeen, AB24 3UE, UK \\ ${ }^{2}$ School of Engineering and Built Environment, Glasgow Caledonian University, 70 Cowcaddens Road, Glasgow, G4 0BA, UK \\ ${ }^{3}$ Department of Electronic \& Electrical Engineering, Faculty of Engineering, University of Strathclyde, G1 1XW, UK \\ Corresponding Author: yasen.harrye@abdn.ac.uk
}

\begin{abstract}
This paper presents a new structure of a power sharing controller for a modular based dual active bridge (DAB) DC/DC converter. The modular topology is based on input-series output-parallel (ISOP) connection of DAB modules suitable for a voltage step down application at medium voltage level. Since DAB has bi-directional power flow capability, this connection would act as its dual input-parallel output-series (IPOS) counterpart in the case of reverse power flow. The proposed power sharing controller ensures uniform power sharing among the modules even in the case of parameter mismatches as well as manages converter operation during pole-to-pole and individual module DC faults. Results for the proposed controller are justified using a detailed Matlab simulation model.
\end{abstract}

Keywords- Dual active bridge (DAB), input-parallel output series (IPOS), input-series output-parallel (ISOP), medium voltage DC (MVDC), power sharing.

\section{INTRODUCTION}

Electrical power generation and distribution is currently witnessing rapid and unprecedented challenges. This is due to a large-scale integration of clean sustainable renewable energy sources with stochastic nature into the grid. Moreover, increased demand for electrical energy by consumers and aging $\mathrm{AC}$ networks requires means to reinforce and increase bulk power evacuation to main load centres [1]. At the present, the renewable energy target for the UK government by 2020 is to achieve $15 \%$ of its energy from renewable sources [2, 3]. Within Europe, the drive to produce large proportion of renewable energy has led to rapid development of large-scale onshore and offshore wind energy generation [4, 5]. With trends to move a large proportion of wind farms clusters to offshore, into deeper waters, (due to local planning constraints and high average wind speeds), connecting offshore wind energy to a distant terrestrial power grid that serves end users has become a challenge [4,5]. Currently, most of these wind farms are connected using standard $33 \mathrm{kV}$ high voltage alternating current (HVAC) collection circuits using solid dielectric cable links. This is due to the power generated by wind turbines and the existing terrestrial transmission grid operated by transmission systems operators (TSO) being AC. However, several challenges are emerging as new wind turbine generators (WTG) are moved further into open seas and power generation capacity of this offshore wind farm parks continues to increase, using traditional HVAC transmission will present challenges that include higher losses and capacity issues for some existing HVAC transmission networks [6]. Thus, multi-terminal HVDC grid is currently been promoted as favourable choice and complement AC transmission, facilitating transmission of renewable energy [6, 7]. There are several principle issues that includes, DC voltage regulation, fast fault isolation and protection, power flow control, maintaining the reliability of the grid, interconnections of different power lines, lack of standardisation and establishment of DC grid code currently preventing widespread deployment of DC grid [8].

This paper focuses on one of the popular topologies of twostage bi-directional DC/DC converters; the dual active bridge (DAB) converter [9] in order to address the problems of DC voltage regulation, fast fault isolation and power flow control. The converter allows soft switching and offers high efficiency for a wide load range, but when a single DAB DC-DC converter is scaled up to higher voltage and power, two potential issues result [10]. The AC coupling transformer incorporated in the converter plays a significant role of voltage transformation and galvanic isolation. But, for application involving high voltages, a high $d v / d t$ stress will result due to the two-level AC voltages that induces an extra stress on transformer insulation and in extreme cases, a complete insulation failure can occur. A second challenge is the selection of the optimum power converter operating frequency. Under high switching frequency of operation, instead of traditional line frequency, weight and volume reduction can be achieved, but an increase in transformer core and winding losses occurs [11-12]. Core losses result due to the raise in eddy current and hysteresis, while the problems of proximity and skin effects will contribute to the winding losses as the switching frequency is increased. An extra cost overhead associated with requirements for additional transformer cooling equipment and a robust insulation strength 
material must be weighed against the impact of the converter failure [12].

Therefore, to meet high voltage blocking and current carrying capability, power switches are required to be connected in series and parallel. Series connection of large number of switches requires even sharing of the total link voltage whilst, equal current sharing is required for the parallel switches. This entails complicated techniques to ensure voltage and current sharing at switch level, increase in snubber circuits while advantages such as converter reshaping, interleaving, and sizing are lost. Modular DAB converter connection is seen as promising converter architecture in medium voltage applications if appropriately scaled up by stacking multiple low-power low-voltage modules. In addition to higher overall power and voltage operation, the modular approach allows for redundancy implementation hence improved fault tolerance, expandability and ease of maintenance [13]. Also, since individual converter modules handle lower power, component stresses are reduced and thermal design is easier [14].

A modular parallel-series DC-DC converter can be connected in either input-series output-parallel (ISOP), input-series output-series (ISOS), input-parallel output-parallel (IPOP) and input-parallel output-series (IPOS).The input series connection enables voltage sharing among the modules, thus leading to a reduced voltage conversion ratio per module. The parallel connection of the modules is used for applications involving a high input/output current sub-division among the modules [15, 16], with each module subjected to reduced current stress, due to current sharing of the parallel connected modules. This will simplify the converter design and manufacture rather than a single dedicated high power converter topology managing all the power. A modularised DAB topology has been reported in [17-18]. Interleaved modular DAB for a micro-grid application was presented in [19] to achieve a high power density by reducing the size of DC filter capacitors through interleaving. In [20], a back to back ISOS DAB for installation at $6.6 \mathrm{kV}$ power distribution systems was proposed.

In this paper, IPOS connection [18] of DAB will be considered for its potential use in step up DC/DC conversion with high input-current high output-voltage characteristics. When the converter is operating in reverse power flow, this configuration becomes its dual counterpart; the ISOP connection for step down operation. A new power sharing controller is proposed to ensure uniform current/voltage sharing among the multi-module structure taking into account the bi-directional power flow characteristic of the converter, possible parameter mismatches and fault scenarios at module and converter levels. The controller structure is based on the authors' open loop neural network (NN) controller proposed for DAB control in [21] to minimize reactive power using triple phase shift (TPS) control. However, the open loop nature of the preceding controller means there is no guarantee in meeting the desired reference power. Therefore, the proposed controller in this paper uses closed loop mechanism to correct reference power input to $\mathrm{NN}$ controller at module level to determine the necessary phase shift ratios to ensure uniform sharing.

The structure of the rest of the paper is as follows. Modular DAB converter topology under TPS control and the proposed power sharing control are discussed in section II. In order to validate the performance of the controller, results are given in section III. In section IV, conclusions of the important points in this paper are noted.

\section{MODULAR DAB CONVERTER}

\section{A. Converter control using triple phase shift modulation}

Fig. 1 depicts the circuit diagram for the $k$-module IPOS/ISOP connected DAB and Fig.2 shows the typical waveforms for one DAB module controlled using triple phase shift (TPS) control, where $D_{1}, D_{2}$ and $D_{3}$ are the three phase shift ratios and the direction of power flow depends on the $\operatorname{sign} D_{3}$.

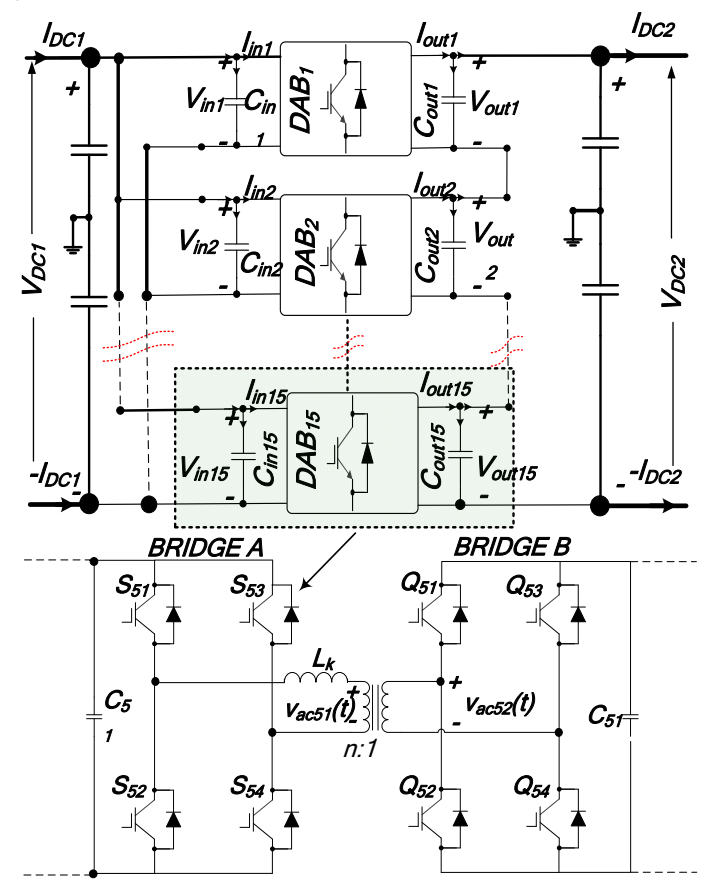

Fig 1: Circuit diagram of modular ISOP/IPOS connected DAB.

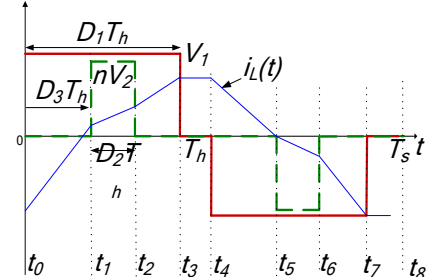

(a)

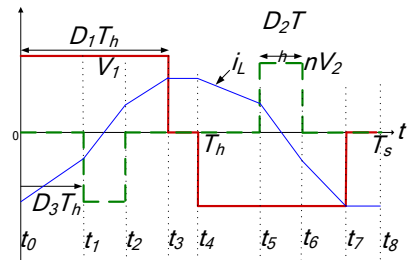

(b)
Fig.2: DAB voltage and current waveforms for TPS control (a) Forward power flow (Bridge A to B) (b) Reverse power flow (Bridge $\mathrm{B}$ to $\mathrm{A}$ ). 


\section{B. Proposed power sharing controller}

In ISOP configurations, it has been reported in [10] that controlling input voltages to achieve input voltage sharing (IVS) is essential for a stable operation of the converter. It automatically ensures output current sharing (OCS) and any attempt to control the output currents to achieve OCS will not be successful because the control strategy is inherently unstable. In IPOS configurations, it is equally stable to control input currents or output voltages [22]. Taking into consideration that bi-directional DAB will be ISOP/IPOS configuration depending on the power flow direction, it is therefore possible to achieve uniform power sharing in both directions using solely a voltage sharing controller on the series-connected side of the converter. The topology of the proposed controller is shown in Fig. 3.

The proposed control scheme consists of:

- A NN based TPS reactive power minimization controller (See author's paper [23]) which takes DAB's per unit desired power transfer as input and generates optimal phase ratios $D_{\text {lopt }}, D_{2 o p t}$ and $D_{3 o p t}$.

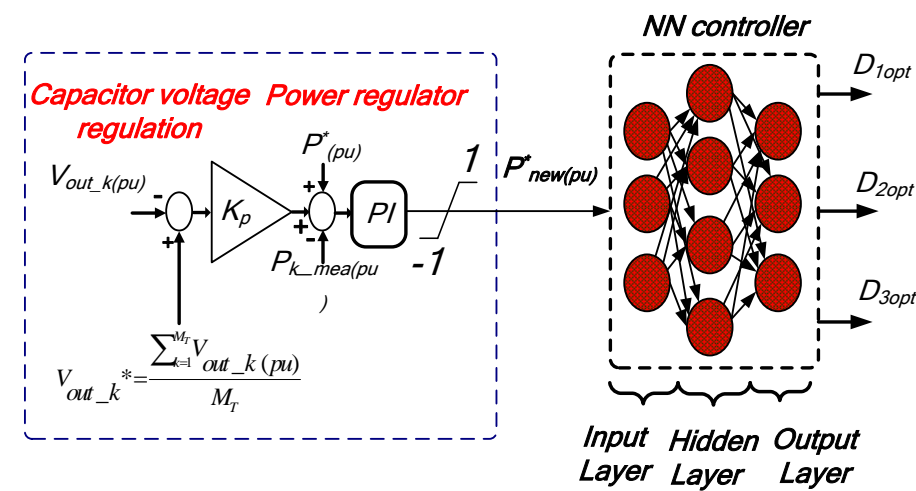

Fig. 3: Proposed power sharing controller structure

- A power sharing loop which adjusts the reference power $P^{*}$ according to an average capacitor voltage regulation/sharing loop where individual module reference capacitor voltage $V_{\text {out } k} *$ is calculated as an average of the $N$-connected converter modules.

The output from the capacitor voltage regulation loop adjusts individual module power requirements to account for charge/discharge level of module input/output capacitors accordingly. Finally, the regulated controller output of the inner loop slightly adjusts the reference power for the NN controller which in turn introduces a small variation to the TPS control variables, $D_{\text {lopt }}, D_{2 o p t}$ and $D_{3 o p t}$. This will ensure equal sharing of voltages on the series connected side and inherently equal current sharing on the parallel connected side of the converter while maintaining minimum reactive power circulation.

\section{SIMULATION AND RESUltS}

A Matlab-Simulink model is built for a $40 \mathrm{MW} 2.5 \mathrm{kV} / 10 \mathrm{kV}$ 4-module IPOS/ISOP connected DAB to validate operation of the proposed power sharing controller under various operating scenarios. The controller is challenged by introducing a $10 \%$ mismatch in module 1 input/output capacitors as well as the transformer turns ratio.

Table 1: Simulation test system parameters

\begin{tabular}{|l|l|l|l|l|}
\hline Parameter & $\begin{array}{c}\text { Module } \\
\mathbf{1}\end{array}$ & $\begin{array}{c}\text { Module } \\
\mathbf{2}\end{array}$ & $\begin{array}{c}\text { Module } \\
\mathbf{3}\end{array}$ & $\begin{array}{c}\text { Module } \\
\mathbf{4}\end{array}$ \\
\hline$P$ & $10 \mathrm{MW}$ & $10 \mathrm{MW}$ & $10 \mathrm{MW}$ & $10 \mathrm{MW}$ \\
\hline$V_{\text {in }}$ & $2.5 \mathrm{kV}$ & $2.5 \mathrm{kV}$ & $2.5 \mathrm{kV}$ & $2.5 \mathrm{kV}$ \\
\hline$V_{\text {out }}$ & $2.5 \mathrm{kV}$ & $2.5 \mathrm{kV}$ & $2.5 \mathrm{kV}$ & $2.5 \mathrm{kV}$ \\
\hline $\begin{array}{l}\text { Switching } \\
\text { frequency } f_{s}\end{array}$ & $1 \mathrm{kHz}$ & $1 \mathrm{kHz}$ & $1 \mathrm{kHz}$ & $1 \mathrm{kHz}$ \\
\hline$C_{\text {in }}$ & $190 \mu \mathrm{F}$ & $200 \mu \mathrm{F}$ & $200 \mu \mathrm{F}$ & $200 \mu \mathrm{F}$ \\
\hline$C_{\text {out }}$ & $290 \mu \mathrm{F}$ & $300 \mu \mathrm{F}$ & $300 \mu \mathrm{F}$ & $300 \mu \mathrm{F}$ \\
\hline $\begin{array}{l}\text { Transformer turns } \\
\text { ratio } n\end{array}$ & 0.9 & 1 & 1 & 1 \\
\hline
\end{tabular}

\section{A. Full power reversal}

Fig. 4 shows simulation results for converter operation at full rated $40 \mathrm{MW}$ power in forward $(\mathrm{t}<1.5 \mathrm{~s})$ and reverse $(\mathrm{t}>1.5 \mathrm{~s})$ directions. The results show that despite the module parameter mismatches, the proposed controller

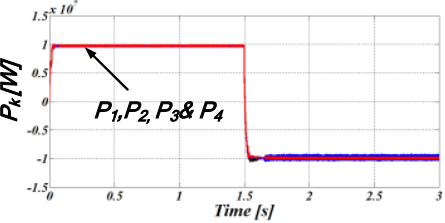

(a)

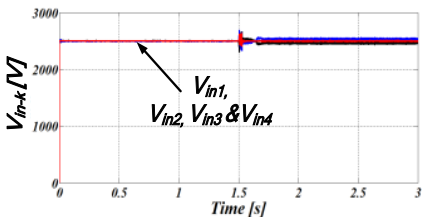

(c)

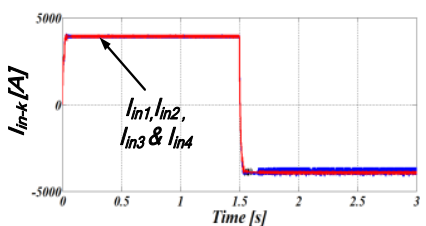

(e)

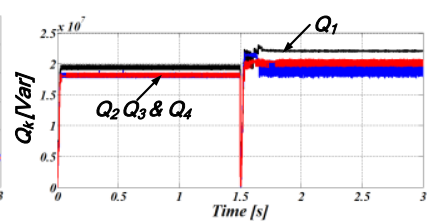

(b)

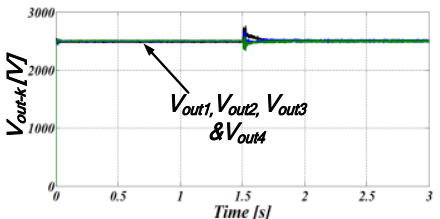

(d)

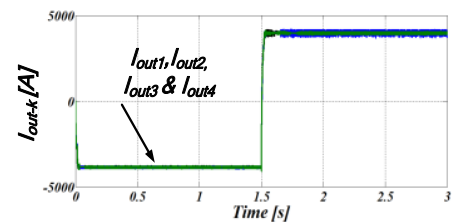

(f)

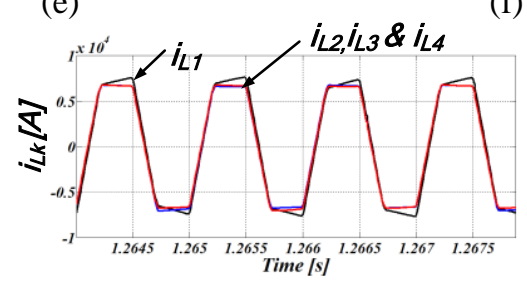

(g)

Fig. 4: Simulation results during full loading conditions (a) active power, (b) reactive power, (c) module input voltages, (d) module output voltages, (e) module input DC currents (f) module output DC currents, and (i) module AC inductor currents. 
is successful in maintaining equal share of voltages and currents (and hence power) among the 4 modules. AC peak current is higher for module 1 (and hence the reactive power) to compensate for the $10 \%$ reduction in the turns ratio to keep power balanced among the modules.

\section{B. DC fault response}

Generally, for the modular DAB DC-DC converter to be a feasible solution for high power applications, the controller response and recovery to large transients during the fault duration or loss of module(s) has to be analysed. A single $\mathrm{DAB}$ converter, fault inherent protection functionality has been presented in previous chapter. Modular converter should also ensure fault isolation and fast recovery, in addition to accommodating the high voltage and power transfer required, without impacting on the grid efficiency. In the event where module(s) fails, the converter should still operate without interruption. The following general requirements need to be addressed regardless of modular bidirectional DAB converter structure.

- The modules should be designed to handle overvoltage and high transient fault currents magnitudes during the fault duration.

- Controller should stably ensure fast fault control/management and recovery once the fault is cleared or faulty module is isolated.

- Endurance of the controller as a result of failure of one or more modules by either rearranging the power circuit or transferring the extra loading to redundant modules, seamlessly with minimum interruption and transient effects.

- Faulty module should be capable of withstanding the fault currents for enough duration, allowing it to be safely isolated from the rest of the system in the event of permanent DC fault.

DC faults in modular DC-DC converter can be categorised into:

- External pole to pole DC link faults.

- Internal faults within the converter modules.

This is achieved by adding fault management mechanism to the proposed controller as described by the flowchart diagram of Fig. 5. Fig. 6 shows results for a pole-to-pole DC fault at the $10 \mathrm{kV}$ side and the response of the proposed controller during and post fault. During the fault on the $V_{\text {out }}$ side, the individual module output voltages drop to zero and due to the current-like characteristics of DAB, the input side currents also drop to zero, which means that the DAB has inherently and naturally isolated the DC fault on the opposite side. The module input side voltages are balanced/equal by connection. The AC link currents are balanced before, during and post fault showing that the proposed controller is successfully operating. Although active power transfer drops to zero during the fault, the converter continues operation with reactive power circulation as the AC link transformer is yet being fed from the input side. The controller is balancing the reactive power consumption in spite of the module parameter mismatches. Fig. 6 (a) shows the active power transfer of the three modules at time $\mathrm{t}=1 \mathrm{~s}$, when a pole to pole fault is applied.

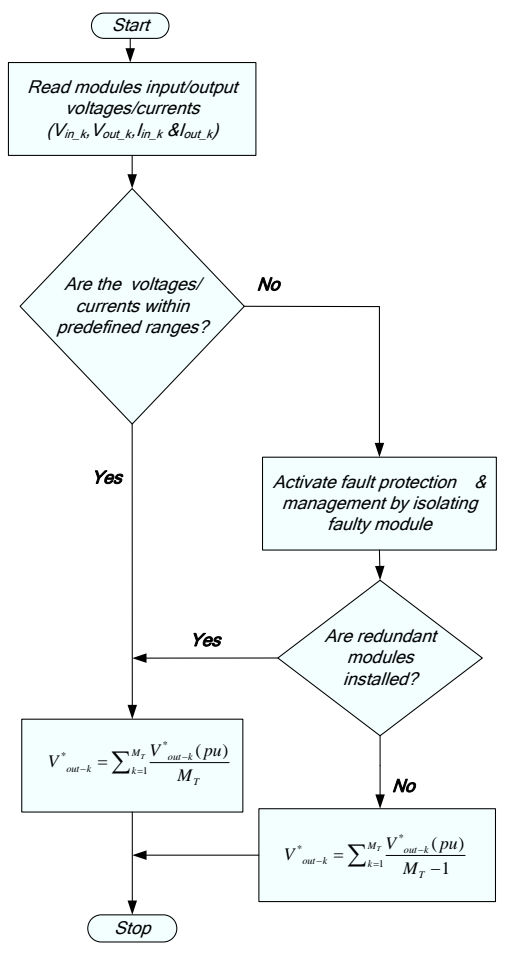

Fig.III: Flow chart of fault isolation mechanism embedded in the power sharing controller.

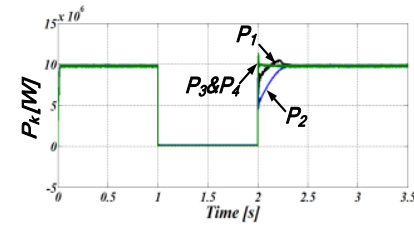

(a)

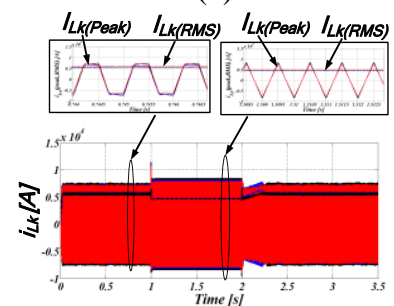

(c)

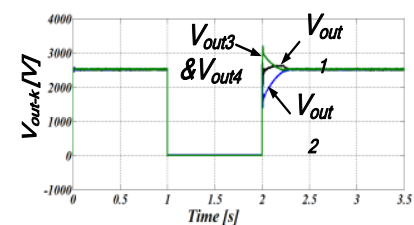

(e)

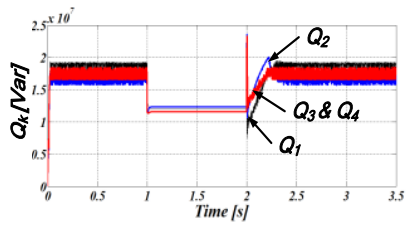

(b)

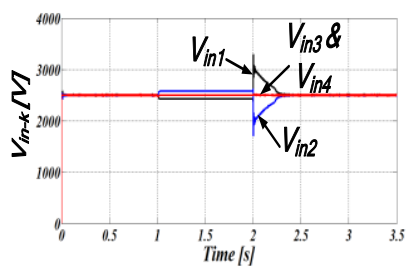

(d)

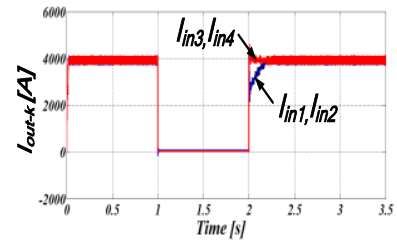

(f)
Fig. 6 Fault simulation results under pole to pole DC fault: (a) active power, (b) reactive power, (c) module AC inductor currents, (d) module input voltages, (d) module output voltages, and (e) module input DC currents. 
There is no active transfer until the temporary fault is cleared and converter resumes regulating at its pre-fault level of $1 \mathrm{pu}$. The circulating reactive power waveforms at pre-fault and during fault operation are illustrated in Fig. 6 (b). Notice that, during the fault duration, there is a small reactive power circulating in the modules, this will not have any contribution to active power transfer nor overheating of the semiconductor switches. The modules superimposed AC terminal voltages $v_{a c l k}$ and $v_{a c 2 k}$ results are demonstrated in Fig. 6 parts (c) and (d). Fig 5 (e) shows the inductor/transformer AC currents $i_{L k}$ for the respective modules.

The fault analysis of a single module failure shown in Fig. 7 labelled as B, is performed in this section. No back-up modules are installed, but rather, the remaining non-faulty modules are overrated to handle extra voltages and currents from the faulty module. Moreover, terminal $V_{D C l}$ is sourcing power of $1 \mathrm{pu}$ before capacitor $C_{\text {out } 1}$ is short circuited at time $\mathrm{t}=1 s$. The implication of shorting $C_{\text {out } 1}$ at the series terminal means a large voltage step, output voltage and input current for the remaining healthy modules. The power sharing controller, should stably regulate the converter and ensure the rest of modules share the output voltage equally without been affected by the large transient. The simulation results obtained for this test are shown in Fig.7.

In Fig. 7 (a), active power result for the three modules is shown. Observe that the faulted module power collapses to zero whilst the remaining modules reconfigure automatically in order to share module 1 power equally. Fig. 7 (b), illustrates the reactive power result, even though module 1 output is short circuited, reactive power will continue to circulate. The AC side voltages and currents are shown in Fig. 7 parts (c) to (d). The non-faulty side of the transformer voltage shown in Fig. 7 (c) is unaffected by the fault, but observe that, the plot of Fig. 7 (d) shows the $v_{a c 21}$ of the faulty module drop to zero. The controller redistributes the voltage between module 2 and 3 , as manifested in transformer terminal voltages. The instantaneous and RMS transformer/inductor current simulation waveform is shown in Fig. 7 (e). The peak current value remains unaffected during the fault period, while the RMS fault current of the modules which is shown by the dotted line, decreases as expected. The modules DC simulation results are presented in Fig 7 parts (f) to (i). By virtue of parallel connection, the overlaid input capacitor voltages $V_{i n 1}, \quad V i_{n 2} \& V_{i n 3}$ of the non-faulted bridges are unaffected. The faulted bridge module1 $V_{\text {out }}$ voltage collapses to zero. The OVS controller redistributes successfully the DC link voltage $V_{D C 2}$, among the healthy modules, as shown in Fig. $7(\mathrm{~g})$. As seen in Fig. $7(\mathrm{~g})$, during the fault, the importance role of fault management and protection algorithm is evident. A new reference voltage to the OVS outer loop of the controller is defined and the remaining non-faulted modules share the DC link voltage equally. Fig. 7 parts (h) and (i) show the input and output DC currents. The input current for the faulty module 1 is controlled to zero whilst the remaining non-faulty modules are unaffected. The output DC current shown Fig. 7 (i) of the modules in the series side

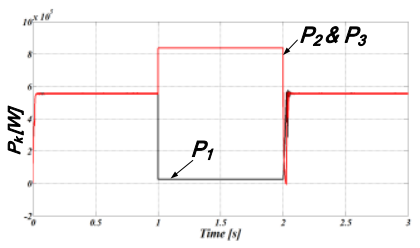

(a)

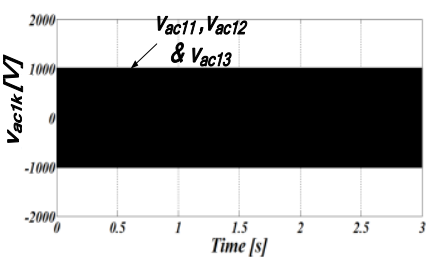

(c)

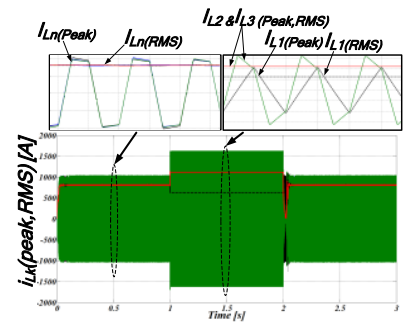

(e)

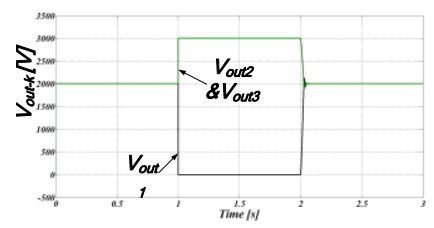

(g)

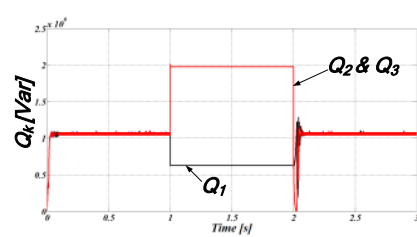

(b)

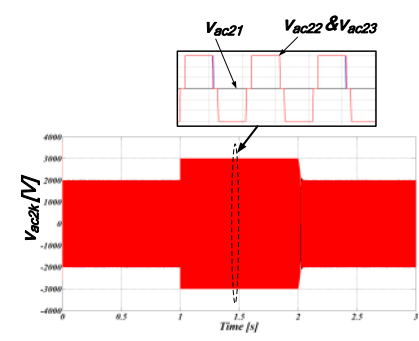

(d)

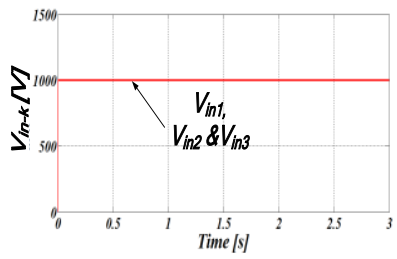

(f)

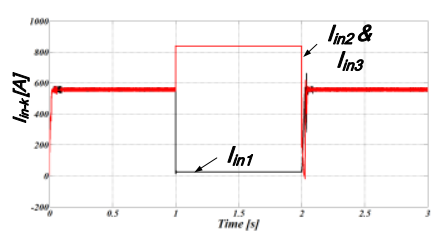

(h)

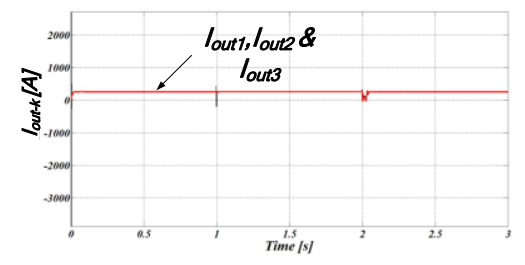

(i)

Fig.7: Fault simulation results when $\mathrm{C}_{\text {out1 }}$ short circuit fault, (a) reference power, (b) reactive power, (c) $\mathrm{DAB}_{1} \mathrm{AC}$ voltage, (d) $\mathrm{DAB}_{2} \mathrm{AC}$ voltage, (e) Inductor/transformer current, (f) DC voltage $V_{D C 1 \_k}$, (g) Terminal $2 \mathrm{DC}$ voltage $V_{D C 2 \_k}$, (h) DC current $I_{\text {in_k }}$, and (i) DC current $I_{\text {out_k }}$. 
continues to be shared equally during the fault period. Thanks to the modularity, the faulty module is bypassed successfully and converter continues to operate without blocking the entire modular converter, by reconfiguring the power circuit.

\section{CONCLUSIONS}

This paper presented a new power sharing controller for dual active bridge connected in multi-modular structure; particularly IPOS/ISOP connection. The proposed controller takes into account voltage/current sharing requirements for series-parallel connections in bi-directional power flow directions and suggests a corrective mechanism using control of the series-connected module capacitor voltages to the module reference power. In addition, with integrated fault protection and management algorithm, results have shown that the proposed controller produced good power sharing results under high module mismatch conditions in two extreme scenarios of full rated power and DC faults.

\section{REFERENCES}

[1] https://www.gov.uk/government/uploads/system/uploads/at tachment_data/file/48274/4263-ensgFull.pdf

[2] http://nationalgridconnecting.com/hitting-the-renewablesgoal/

[3] https://www.gov.uk/government/uploads/system/uploads/at tachment_data/file/523365/Major_projects_status_update_s ummary_April_2016.pdf

[4] A. Arapogianni, "Deep Water. The next step for offshore wind energy report. European Wind Energy Association (EWEA), 2013.

[5] A. Arapogianni, "Wind in our Sails. The coming of Europe's offshore wind energy industry report". European Wind Energy Association (EWEA), 2011.

[6] D. Jovcic and K. Ahmed, High Voltage Direct Transmission, Converters, Systems and DC Grids. Wiley 2015.

[7] M. Hajian, D. Jovcic and B. Wu, "Evaluation of Semiconductor Based Methods for Fault Isolation on High Voltage DC Grids," IEEE Trans. on Smart Grids, Vol. 4, Issue 2, June 2013, pp: 1171-1179.

[8] D. Jovcic, M. Taherbaneh, J.P. Taisne, S. Nguefeu, "Offshore DC Grids as an Interconnection of Radial Systems: Protection and Control Aspects", Smart grid, IEEE Transactions on, vol. 6, pp.903-910, 2015.

[9] R. W. De Doncker, D. M. Divan, and M. H. Kheraluwala, "A three phase soft-switched high power density DC/DC converter for high power applications," in Conf. Rec. IEEE IAS Annu. Meeting, Pittsburgh, PA,Oct. 2-7, 1988, pp. 796-805.

[10] G. P. Adam, I. A. Gowaid, S. J. Finney, D. Holliday and B. W. Williams, "Review of dc-dc converters for multiterminal HVDC transmission networks," in IET Power Electronics, vol. 9, no. 2, pp. 281-296, 2102016.

[11] Drofenik, U., "A 150kW Medium Frequency Transformer Optimized for Maximum Power Density," Integrated Power Electronics Systems (CIPS), 2012 7th International Conference on , vol., no., pp.1,6, 6-8 March 2012.

[12] T. Lüth, M. M. C. Merlin, T. C. Green, F. Hassan and C. D. Barker, "High-Frequency Operation of a DC/AC/DC System for HVDC Applications," in IEEE Transactions on
Power Electronics, vol. 29, no. 8, pp. 4107-4115, Aug. 2014.

[13] R. H. Wu, T. Kohama, Y. Kodera, T. Ninomiya, and F. Ihara, "Load-current-sharing control for parallel operation of DC-to-DC converters," in Power Electronics Specialists Conference, 1993. PESC '93 Record, 24th Annual IEEE, 1993, pp. 101-107.

[14] N. Denniston, A. M. Massoud, S. Ahmed, and P. N. Enjeti, "Multiple-Module High-Gain High-Voltage DC-DC Transformers for Offshore Wind Energy Systems," Industrial Electronics, IEEE Transactions on, vol. 58, pp. 1877-1886, 2011.

[15] R. Ayyanar, R. Giri and N. Mohan, "Active input-voltage and load-current sharing in input-series and output-parallel connected modular DC-DC converters using dynamic input-voltage reference scheme," in IEEE Transactions on Power Electronics, vol. 19, no. 6, pp. 1462-1473, Nov. 2004.

[16] W. Chen, X. Ruan, H. Yan and C. K. Tse, "DC/DC Conversion Systems Consisting of Multiple Converter Modules: Stability, Control, and Experimental Verifications," in IEEE Transactions on Power Electronics, vol. 24, no. 6, pp. 1463-1474, June 2009.

[17] H. Zhou, Tran Duong, Siew Tuck Sing and A. M. Khambadkone, "Interleaved bi-directional Dual Active Bridge DC-DC converter for interfacing ultracapacitor in micro-grid application," 2010 IEEE International Symposium on Industrial Electronics, Bari, 2010, pp. 22292234.

[18] H. Akagi and R. Kitada, "Control and Design of a Modular Multilevel Cascade BTB System Using Bidirectional Isolated DC/DC Converters," in IEEE Transactions on Power Electronics, vol. 26, no. 9, pp. 2457-2464, Sept. 2011.

[19] Zumel, P.; Ortega, L.; Lazaro, A.; Fernandez, C.; Barrado, A.; Rodriguez, A.; Hernando, M.M., "Modular dual active bridge converter architecture," Applied Power Electronics Conference and Exposition (APEC), 2014 Twenty-Ninth Annual IEEE , vol., no., pp.1081,1087, 16-20 March 2014.

[20] Haifeng Fan; Hui Li, "High-Frequency Transformer Isolated Bidirectional DC-DC Converter Modules With High Efficiency Over Wide Load Range for $20 \mathrm{kVA}$ SolidState Transformer," Power Electronics, IEEE Transactions on , vol.26, no.12, pp.3599,3608, Dec. 2011.

[21] F. Haifeng and L. Hui, "High-Frequency Transformer Isolated Bidirectional DC-DC Converter Modules With High Efficiency Over Wide Load Range for 20 kVA SolidState Transformer," Power Electronics, IEEE Transactions on, vol. 26, pp. 3599-3608, 2011

[22] C. Wu, R. Xinbo, Y. Hong, and C. K. Tse, "DC/DC Conversion Systems Consisting of Multiple Converter Modules: Stability, Control, and Experimental Verifications," Power Electronics, IEEE Transactions on, vol. 24, pp. 1463-1474, 2009.

[23] Y. Harrye, A.A. Aboushady, and K.H. Ahmed, 'Dual Active Bridge DC/DC Converter Reactive Power Minimization with Triple Phase Shift Control using Open Loop Neural Network Controller', IEEE ICRERA conference, October 2014, pp. 566-571. 